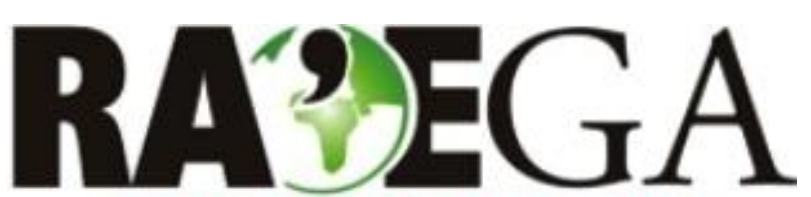

O ESPAÇO GEOGRÁFICO EM ANÁLISE

\title{
EFICIÊNCIA SOCIAL, ECONÔMICA E AMBIENTAL DOS ASSENTAMENTOS RURAIS DO PANTANAL SUL
}

\section{SOCIAL, ECONOMIC AND ENVIRONMENTAL EFFICIENCY OF RURAL SETTLEMENTS IN SOUTH PANTANAL}

\author{
Jorge de Souza Pinto ${ }^{1}$, Edgar Aparecido da Costa ${ }^{2}$, Daniel Massen Frainer ${ }^{3}$, Ademir Kleber \\ Morbeck de Oliveira ${ }^{4}$, Celso Correia de Souza ${ }^{5}$
}

\section{RESUMO}

Neste estudo buscou-se analisar e avaliar a eficiência da agricultura nos assentamentos rurais de Corumbá e Ladário, estado de Mato Grosso do Sul, focando em indicadores de desenvolvimento social, econômico e ambiental. Foi realizada uma coleta de dados exploratória amostral com aplicação de formulário em 270 camponeses nos assentamentos 72, de Ladário; Taquaral, Tamarineiro Il e Paiolzinho, de Corumbá/MS. A análise dos dados foi obtida mediante aplicação do modelo $D E A / C C R$ para obtenção das fronteiras de eficiência da agricultura nos assentamentos. $\mathrm{Na}$ análise individualizada em cada um dos assentamentos obteve-se o resultado de que $12 \%$ das DMU's (propriedades individuais) apresentam índice alto de eficiência de sustentabilidade e que $37 \%$ e $51 \%$ apresentam índices médio e baixo de eficiência de sustentabilidade, respectivamente. Quando comparadas no conjunto das amostras de todos os assentamentos 30\% das DMU's apresentam índice alto de eficiência de sustentabilidade, enquanto $62 \%$ e $8 \%$ das DMU's apresentam índices médio e baixo, respectivamente. Os resultados indicam um cenário em que se faz necessária a adoção de políticas que priorizem a recuperação e manutenção da agricultura camponesa na região do Pantanal como forma de fomentar a preservação e conservação do ambiente, da condição social, econômica e ambiental dos camponeses e do desenvolvimento regional.

PALAVRAS-CHAVE: Agricultura familiar; Agroecologia; Desenvolvimento territorial; Sustentabilidade.

\section{ABSTRACT}

In this study we aimed to analyze and evaluate the efficiency of agriculture in the rural settlements of Corumba and Ladario, in Mato Grosso do Sul (MS), focusing on indicators of social, economic and environmental development. An exploratory sampling data collection was carried out on 270 farmers in 72 settlements of Ladario; Taquaral, Tamarineiro II and Paiolzinho in Corumba, MS with an application form. Data analysis was obtained by applying the DEA/CCR model to obtain the agriculture efficiency of borders in the settlements. The individual analysis for each of the settlements showed $12 \%$ of the DMU's (single property) with a higher rate of efficiency and sustainability of $37 \%$ and $51 \%$ for medium-low and sustainable levels of efficiency, respectively. When compared to all samples of all settlements $30 \%$ of DMU's present high level of sustainability efficiency, while $62 \%$ and $8 \%$ of DMU's present average and low rates, respectively. The results indicate a scenario where it is necessary to adopt policies that prioritize peasant agriculture recovery and maintenance of the Pantanal region as a way of promoting the preservation and conservation of the environment, the social, economic and environmental condition of farmers and the regional development.

KEY-WORDS: Family farming; Agroecology; Territorial Development; Sustainability

\section{Recebido em: 11/06/2015}

Aceito em: 29/04/2017

\footnotetext{
${ }^{1}$ Universidade Federal do Mato Grosso do Sul, Corumbá/MS e-mail: jorge.pinto@ufms.br

${ }^{2}$ Universidade Federal do Mato Grosso do Sul, Corumbá/MS, e-mail: edgarac10@gmail.com

${ }^{3}$ Universidade Estadual de Mato Grosso do Sul, Corumbá/RS e-mail: danielfrainer@uems.br

${ }^{4}$ Universidade Anhanguera-Uniderp, Corumbá/MS e-mail: akmorbeckoliveira@gmail.com

${ }^{5}$ Universidade Anhanguera-Uniderp, Corumbá/MS e-mail: csouza939@gmail.com
} 


\section{INTRODUÇÃO}

No Brasil, os assentamentos rurais agrupam uma parcela significativa de trabalhadoras e trabalhadores que lutam contra um destino relacionado a muitas mazelas sociais de exclusão e miséria, moldado, em grande parte, pelo enfrentamento da questão agrária. Iniciativas como essas pressionam o governo a melhorar a distribuição de terra e elaborar políticas de apoio à agricultura de base familiar (TEÓFILO; MENDONÇA, 2001).

O censo agropecuário IBGE (2006) indicou a agricultura familiar como responsável por $38,0 \%$ do valor total da produção dos estabelecimentos rurais. Contudo, 31\% desses agricultores declararam não ter obtido nenhuma renda proveniente dos trabalhos em suas propriedades rurais no período. Logicamente que essa informação não pressupõe, de imediato, o fracasso produtivo dessa parcela de produtores. Demonstra, contudo, que não desejaram ou não conseguiram se inserir nas políticas públicas de comercialização de alimentos, como Programa de Aquisição de Alimentos (PAA) e Programa Nacional de Alimentação Escolar (PNAE).

Os resultados mostraram, ainda, uma estrutura agrária concentrada no país: os estabelecimentos não familiares, apesar de representarem $15,6 \%$ do total, ocupavam $75,7 \%$. A área média dos estabelecimentos familiares foi de 18,37 hectares e a dos não familiares, de 309,18 hectares. Foram registradas 12,3 milhões de pessoas vinculadas à agricultura familiar, sendo a maioria de homens (2/3), apesar de apontar um número expressivo de mulheres - 4,1 milhões (1/3 dos ocupados) (IBGE, 2006). Cabe esclarecer que, em conformidade com Fernandes (2001), este trabalho entende a agricultura familiar como uma condição da organização do trabalho camponês.

Para além desses resultados, a experiência dos trabalhos realizados em vários assentamentos rurais tem indicado que a falta de coesão territorial tem sido um dos principais gargalos do desenvolvimento territorial rural. Invariavelmente são instaladas famílias diferentes, sem laços de vizinhança e de confiança, elementos primordiais na vida camponesa. Essa condição incita para o isolamento da família no seu território (a parcela, o lote), deixando de participar de organizações associativas e cooperativas.

A experiência na lida com a terra de cada família camponesa é determinante no arranjo que imprime no seu lote e, quando somadas às experimentações do novo, induzem novas territorialidades. Para Saquet (2007, 2008), territorialidade significa organização, participação e atuação política. É um fator de modificação territorial e de lugar. Através do seu estudo se reconhece as pessoas em suas necessidades, identidades e anseios pessoais, de cada ser e de cada família. Para Saquet e Alves (2014, p. 8), na construção de propostas de desenvolvimento, devem ser tomados em conta "a heterogeneidade dos tempos, dos territórios, das temporalidades (ritmos), das territorialidades e a conquista da autonomia no processo decisório".

O assentamento rural é, portanto, um território composto por vários territórios, todos autônomos e regidos pelo embate entre as vocações produtivas ou não das famílias e das políticas governamentais de desenvolvimento. Considerar as territorialidades camponesas na construção de políticas públicas deve ser a opção mais acertada para aproximar os interesses nos territórios da reforma agrária. A maior eficácia das políticas para o setor rural ocorre de baixo para cima e funciona melhor em pequenas escalas geográficas pela relativa diminuição dos conflitos (COSTA, 2009).

Esse desenvolvimento fica mais fácil de ser levado avante adotando um ordenamento territorial a partir do conhecimento da realidade e do diálogo com e entre seus habitantes. Sua construção provém das forças antagônicas que confluem para interesses diversos e singulares que estimulam práticas, facilitam ou dificultam fluxos, permitem ou inibem a circulação de capitais, atraem ou repelem novos investimentos. Pressupõe aplicação de um conjunto de outros instrumentos para viabilizar a política adotada para múltiplas escalas territoriais. 
Por outro lado, o desenvolvimento rural precisa superar as dicotomias entre o moderno e o atrasado, circular dinâmica e solidariamente através de redes sociais e vínculos institucionais que operem com flexibilidade e transparência, enriquecidas com normas e valores de confiança cidadã, que facilitem a construção de parcerias entre os diferentes atores (ACSELRAD; LEROY, 1999).

Para Martins (2002), o desenvolvimento territorial sustentável, pensado na escala de um assentamento rural, deve ser a expressão do processo de empoderamento da comunidade local, materializando formas que denotem a melhoria da qualidade de suas vidas. 0 desenvolvimento é, antes de tudo, uma postura atrelada à sentimentalidade, implicando, pois, pensá-lo na escala humana.

Ressalta-se que os entendimentos de desenvolvimento territorial e local são adaptados neste trabalho, não caracterizando a necessidade de inserção e competitividade do camponês no mundo das mercadorias. O camponês não é visto como um elemento de fora do contexto capitalista, mas com sua lógica de atuação particularizada e articulação de arranjos para superar a dependência de insumos e da integração aos impérios agroalimentares (PLOEG, 2006; MARQUES, 2008). O desenvolvimento sustentável pode ser alcançado com bases sólidas a partir da consolidação da agroecologia como pano de fundo, e como viabilizadora de condutas produtivas integradas social, econômica e ambientalmente (SAQUET, 2007 e 2008).

Tendo por base os trabalhos de Altieri (1998, 2012) e Gliessman (2000), Saquet e Alves (2014, p. 576) resumem de forma didática (e por isso foram utilizados, apesar da consulta dos textos originais) os princípios mais importantes da agroecologia:

a) ampliação e preservação da biodiversidade; b) aproveitamento de sinergismos próprios dos componentes biológicos e dos recursos de cada unidade produtiva, trabalhando com o controle biológico de pragas; c) recuperação do solo degradado e sua proteção com manejo adequado que garanta matéria orgânica para nutrição das plantas; d) produção de alimentos sem a utilização de insumos químicos; e) contribuição para a conservação das águas, das plantas e dos animais; f) aumento da capacidade de uso múltiplo do território com o favorecimento da diversificação da produção e com as agroflorestas; g) reciclagem de nutrientes e da matéria orgânica; $h$ ) preservação das identidades culturais, valorizando o conhecimento dos agricultores, sua participação nos processos decisórios e favorecendo o uso eficaz dos recursos de cada unidade produtiva; i) tentativa de fortalecer a comercialização direta com o consumidor em mercados locais.

Moreira e Carmo (2004) acrescentam que os princípios da agroecologia perfazem o arcabouço para a consolidação de desenvolvimento sustentável em assentamentos rurais e trazem as seguintes características: 1) integralidade; 2) harmonia e equilíbrio; 3) autonomia de gestão e controle; 4) minimização das externalidades negativas; 5) manutenção e fortalecimento dos circuitos curtos de comercialização; 6) utilização do conhecimento local vinculado aos sistemas tradicionais de manejo dos recursos naturais; 7) pluriatividade, seletividade e complementaridade de rendas.

A agroecologia pressupõe a melhoria da qualidade de vida das pessoas envolvidas, pensada em múltiplas dimensões, trabalhando com alternativas de renda, empoderamento do grupo, elevação da autoestima, construção de força política na escala do território, estímulo ao resgate cultural e os cuidados com o ambiente. Outro aspecto relevante é descobrir se, na prática, a abordagem do desenvolvimento local conseguirá ajudar a produzir coesão territorial, eliminar as barreiras produtivas, melhorar a qualidade de vida e transformar os assentados em protagonistas do seu destino (SAQUET, 2007 e 2008).

Por se tratar de uma área geográfica em contato direto com o Pantanal e, em razão de convicções científicas, assume-se que a agroecologia é uma forma de agricultura que faz bem ao ser humano e ao ambiente. Autores como Altieri (1998), Caporal e Costabeber (2001) 
e Gliessman (2000) vinculam a agroecologia a: "uma produção agrícola", "uma vida mais saudável", "uma forma de trabalhar preservando o ambiente", "tirar alimentos da terra sem esgotar os recursos naturais", "uma agricultura que não destrói o meio ambiente".

A agroecologia encontra terreno fértil nas possibilidades de resistência no campo da agricultura de base familiar, especialmente nos assentamento da reforma agrária. Pode apoiar a criação de instrumentos de vanguarda para permitir adequadas condições sociais aos camponeses com os devidos cuidados com a preservação e conservação do ambiente e dos recursos naturais, como terra e água.

Assim, o objetivo deste estudo é avaliar a eficiência da agricultura nos assentamentos rurais do Pantanal Sul focando em indicadores de desenvolvimento social, econômico e ambiental. Ao mesmo tempo, pretende-se discutir a agroecologia como alternativa para maior eficiência produtiva e bem estar social dos camponeses. A opção por não utilizar indicadores culturais neste ensaio se deu em razão da escolha metodológica. Contudo, ela estará presente nas reflexões ao longo de todo o texto.

Além desta seção introdutória e de balizamento conceitual, o artigo apresenta mais duas seções: a primeira, com os materiais e métodos aplicados na pesquisa de campo e na organização e apresentação das informações; a segunda, com os resultados e a discussão de algumas limitações dos modelos.

\section{MATERIAIS E MÉTODOS}

A área pesquisada está localizada na zona rural dos municípios de Corumbá e Ladário, cujos territórios abarcam grande parte do Pantanal Sul-mato-grossense, integrando a Bacia do Rio Paraguai. As cidades sedes estão situadas a 426 km da capital Campo Grande, distantes a mais de $200 \mathrm{~km}$ da cidade brasileira mais próxima (Miranda-MS), separadas/unidas pelo Pantanal, e a menos de $10 \mathrm{~km}$ das cidades bolivianas fronteiriças (COSTA, 2013).

Corumbá limita-se com os municípios de Cáceres, Poconé, Barão de Melgaço, Santo Antonio do Leverger e Itiquira, ao Norte, no estado de Mato Grosso. No Estado de Mato Grosso do Sul, o município limita-se na porção Leste com Sonora, Coxim, Rio Verde de Mato Grosso, Aquidauana e Miranda, ao Sul com Porto Murtinho, tendo Ladário encravado em seu interior, nas proximidades de sua área urbana principal, tendo a Oeste, a Bolívia (COSTA, 2013).

Os locais de levantamento de dados foram os assentamentos rurais 72, no município de Ladário; Paiolzinho, Tamarineiro II Norte, Tamarineiro II Sul e Taquaral, no município de Corumbá. Conforme Zarate, Santos e Costa (2010), o Assentamento 72 possui uma área total de 2.341,2996 ha, onde foram assentadas 85 famílias, perfazendo uma média de 18,5 ha por lote, estando localizado, entre as coordenadas $19^{\circ} 03^{\prime}$ e $19^{\circ} 07^{\prime}$ de latitude Sul e entre $57^{\circ} 33^{\prime}$ e $57^{\circ} 36^{\prime}$ de longitude Oeste (Figura 1 ).

$\mathrm{O}$ assentamento Taquaral foi implantado em 1991 e está localizado a menos de $10 \mathrm{~km}$ da cidade de Corumbá, entre as coordenadas $19^{\circ} 02^{\prime}$ e $19^{\circ} 10^{\prime}$ de latitude Sul e $57^{\circ} 37^{\prime}$ e $57^{\circ} 44^{\prime}$ de longitude Oeste, com altitude variando de 90 a $540 \mathrm{~m}$. Tem uma área total de 10.013,24 ha dividida em 394 parcelas de dimensões variáveis. 


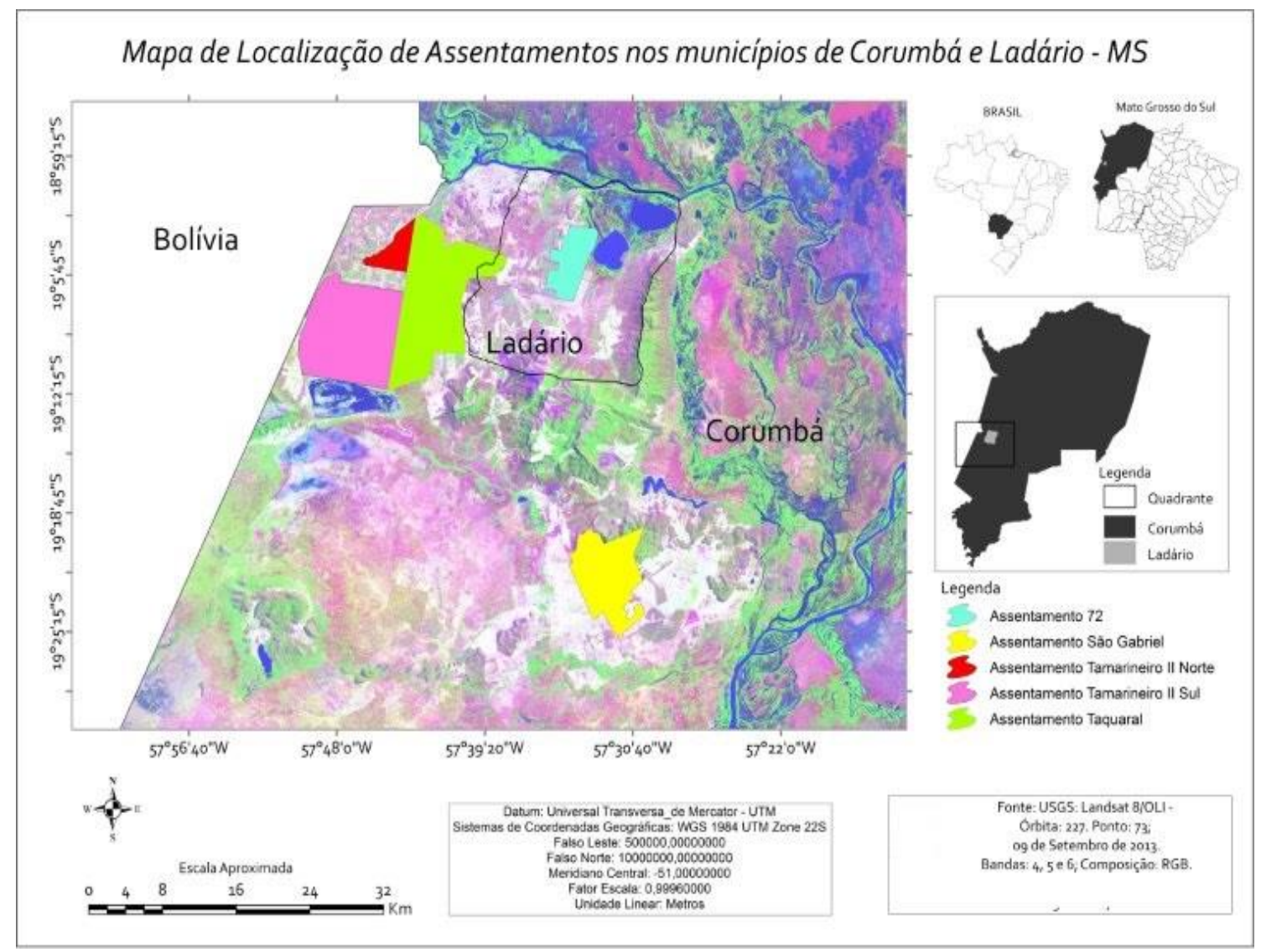

Figura 01 - Área de estudo: assentamentos de Corumbá e Ladário/MS.

O assentamento Tamarineiro II (Norte e Sul) foi implantado em 1995. Encontra-se localizado a sudoeste de Corumbá, acompanhando a fronteira Brasil-Bolívia, com altitude variando de 90 a 400 metros. Possui área total de 10.635,58 ha, divididos em 428 parcelas de dimensões variáveis.

O Assentamento Paiolzinho, implantado em 1999, situa-se entre as coordenadas $19^{\circ} 04^{\prime} \mathrm{e}$ $19^{\circ} 07^{\prime}$ Latitude Sul e $57^{\circ} 44^{\prime}$ e $57^{\circ} 48^{\prime}$ de Longitude Oeste. Possui área total de 1.198, 03 ha e 70 parcelas rurais com tamanho médio de 15,88 ha. Está localizado próximo à fronteira com a Bolívia, dividindo o assentamento Tamarineiro II em Norte e Sul.

Os solos dos assentamentos tratados neste estudo apresentam, de maneira geral, elevada fertilidade natural, capaz de resultar em produtividades relativamente elevadas, mesmo quando não se aplicam fertilizantes. O grande problema produtivo de todos os assentamentos desses municípios é a deficiência hídrica.

As chuvas são irregulares e concentradas no verão, não superando 1.200 mm/anuais. Além disso, falta água própria para o consumo e em quantidade para os sistemas produtivos. Como o solo é rico em argilas, quando chove muito fica encharcado e não permite manejo com máquinas agrícolas. Quando está seco, racha, aparecendo enormes fissuras (Figura 2). Assim, seu uso e manejo são determinantes para obtenção de produções rentáveis e ecologicamente corretas. 


\section{EFICIÊNCIA SOCIAL, ECONÔMICA E AMBIENTAL DOS ASSENTAMENTOS RURAIS DO PANTANAL SUL}

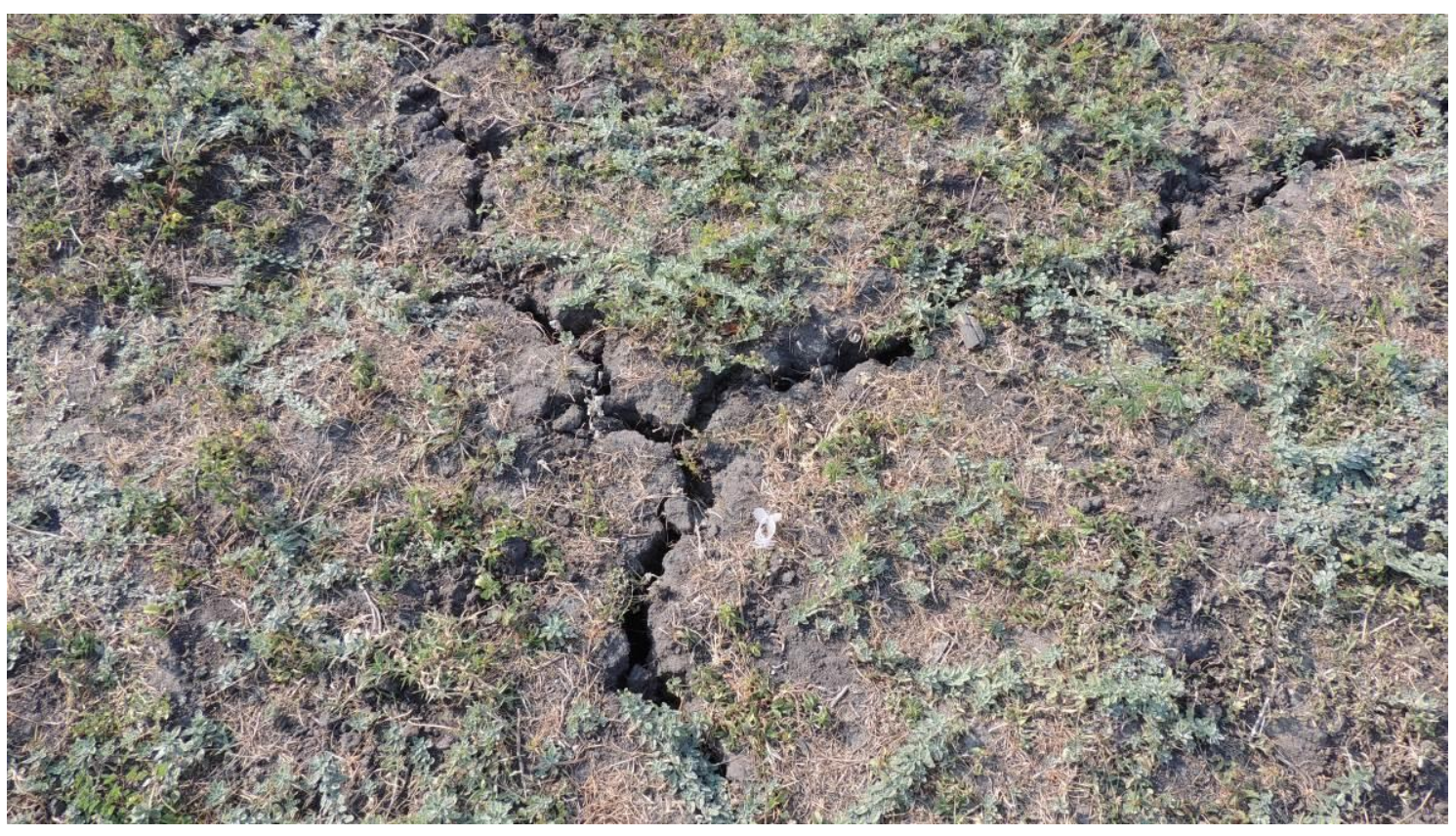

Figura 02 - Fissuras no solo do Assentamento 72, Ladário-MS. Autor: COSTA, E.A., Setembro de 2012.

Pela proximidade das áreas urbanas, os Assentamentos 72 em Ladário, Paiolzinho, Tamarineiro II (Norte e Sul) e Taquaral foram escolhidos para aplicação de um formulário de coleta de dados para análise da eficiência em sustentabilidade das atividades de agricultura de base familiar em suas dependências. Além disso, todos os assentamentos estão nas mesmas condições edafo-climáticas e socioeconômicas de suas populações. Foram aplicados 270 formulários contendo 47 questões, entre objetivas, dicotômicas e abertas, das quais foram selecionadas 13 variáveis para compor a análise pretendida, seguindo a metodologia e conceitos da Data Envelopment Analysis (DEA), ou Análise Envoltória de Dados.

A DEA fornece dois tipos de modelos para análise. Charnes, Cooper e Rhodes (1994) elaboraram o modelo CCR (Iniciais de seus nomes), também conhecido por Constant Returns to Scale (CRS), o qual avalia a eficiência total, determinando as DMUs (Decision Making Units) eficientes da amostra, além de fornecer informação sobre as distâncias das DMUs ineficientes da fronteira de eficiência. Banker, Charnes e Cooper (1984) elaboraram o modelo conhecido como BCC, ou Variable Returns to Scale (VRS). Este modelo, conforme os autores,
“[...] permite a projeção de cada DMU ineficiente sobre a superfície de fronteira (envoltória) determinada pelas DMUs eficientes de tamanho compatível" (SOARES DE MELLO et al., 2005 e 2006).

Para realizar a análise através de um desses dois modelos, existe a necessidade de fixação da ótica de análise, ou seja, se a análise será orientada pelos inputs ou pelos outputs. A análise orientada pelos outputs mantém fixa a quantidade inputs e maximiza proporcionalmente as quantidades de outputs. Já o modelo orientado pelos inputs minimiza proporcionalmente as quantidades de inputs, mantendo fixas as quantidades de outputs (ANGULO-MEZA et al., 2007; SENRA et al., 2007). Na aplicação do DEA neste estudo, foi utilizado o modelo CCR com orientação voltada para a maximização dos inputs.

Neste trabalho, foi considerada a população de 977 famílias de assentados, segundo o INCRA (cada família entendida como uma DMU). Foram utilizadas 13 variáveis de entradas (inputs) e uma variável de saída (output), analisadas a partir do DEA/CCR (portanto, em conformidade com CHARNES, COOPER e RHODES, 1994) e com orientação a input, extraídas do formulário aplicado para 


\section{EFICIÊNCIA SOCIAL, ECONÔMICA E AMBIENTAL DOS ASSENTAMENTOS RURAIS DO PANTANAL SUL}

levantamento de dados, totalizando uma amostra de 270 DMU's.

Para análise dos dados foi utilizado o software livre SIAD V3, de duas maneiras: a) individualmente para cada amostragem dos assentamentos e suas respectivas DMU's e; b) de forma agrupada, analisando a eficiência da amostragem de todos as DMU's dos assentamentos em conjunto, demonstrando-se os resultados em relação ao grupo original e em relação a coletividade das 977 famílias de assentados existentes em todos os assentamentos pesquisados (ANGULO-MEZA et al., 2007; SENRA et al., 2007; SOARES DE MELLO et al., 2005 e 2006).

Quando da aplicação da DEA, realizou-se testes dos dados no software SIAD v3, utilizando os modelos DEA/BCC orientados para input $e$ output e o modelo DEA/CCR orientado para output obtendo-se resultados inconclusivos. Assim, o modelo que melhor foi ajustado às variáveis e DMU's em estudo foi o CCR orientado a input, no qual se obteve os índices de eficiência de sustentabilidade para os assentamentos, individualmente e agrupados. Portanto, a escolha consistiu em reunir as informações coletadas no campo e aplicar cada um dos modelos. O próprio software indicou os inconclusivos e o aceito para avaliação.

As variáveis foram selecionadas a partir da aplicação de um formulário com amostragens que levaram em conta as 977 famílias de assentados, utilizando-se como base as variáveis, insumos e produto, e respectivos escores como apresentados, conforme o Quadro 1.

As variáveis binárias (Sim ou Não) assumiram os valores ( 1 e 0 ), respectivamente. A primeira variável, a renda do assentado, é considerada como produto (output), as outras 13 variáveis são os insumos (inputs), todas construídas para apresentar efeito positivo com a eficiência.

As variáveis de 2 a 7 refletem a infraestrutura econômica, social e de moradia, e foram utilizadas como fatores importantes para a renda do assentado. As variáveis de 9 a 14 foram consideradas para verificação do nível de sustentabilidade ambiental.

$\mathrm{Na}$ análise das variáveis foi empregada a Análise Envoltória de Dados (DEA) orientada para entender a eficiência dos insumos dos assentamentos 72, Paiolzinho, Tamarineiro e Taquaral. A escolha deste modelo deveu-se ao fato de os outputs e inputs utilizados não serem inputs passíveis de serem reduzidos, como determina a lógica do modelo orientado a input, em conformidade com Angulo-Meza et al (2007), Soares de Mello et al (2006) e Soares de Mello et al (2005). 
Quadro 01 - Apresentação descritiva das variáveis de insumos e produto.

\begin{tabular}{|c|c|}
\hline 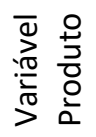 & $\begin{array}{l}\text { 1. Renda média familiar dos assentados em reais, sendo esta a renda total, incluindo venda, } \\
\text { remuneração de trabalhos externos ao lote e benefícios sociais. }\end{array}$ \\
\hline \multirow{6}{*}{ 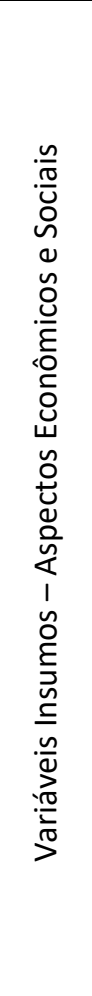 } & $\begin{array}{l}\text { 2. Programa de extensão ofertado pelas escolas aos alunos - variável binária (Sim ou Não), } \\
\text { indicando se programa é oferecido aos alunos: Sim: } 1 \text {; Desconhece: } 0 \text {; Não: } 0 .\end{array}$ \\
\hline & $\begin{array}{l}\text { 3. Curso de capacitação para o trabalhador rural - variável binária (Sim ou Não), indicando se } \\
\text { cursos são oferecidos aos trabalhadores: Sim (1); Desconhece (0); Não (0). }\end{array}$ \\
\hline & $\begin{array}{l}\text { 4. Possibilidades de lazer na região do assentado - variável que indica se existe ou não área } \\
\text { de lazer no assentamento tais como: campos de futebol, salão de festas e outras } \\
\text { infraestruturas para lazer: Não existe infraestrutura de lazer (0); Existem salões de festas ou } \\
\text { campos de futebol (1); Existem campos de futebol e salões de festas (2); Existem campos de } \\
\text { futebol, salões de festas e televisor (3). }\end{array}$ \\
\hline & $\begin{array}{l}\text { 5. Tipo de habitação do assentado - variável que indica o tipo de moradia do assentado } \\
\text { como, por exemplo: casa de taipa, casa de tijolo sem reboco e piso e casa de tijolo com } \\
\text { reboco e piso: Casa de taipa (0); Casa de tijolo sem reboco e piso (1); Casa de tijolo com } \\
\text { reboco e piso (2). }\end{array}$ \\
\hline & $\begin{array}{l}\text { 6. Destino da produção do assentado - foram elencadas as seguintes variáveis: subsistência, } \\
\text { atacadista, varejista, atravessadores e outros: Subsistência e atravessadores (1); } \\
\text { Subsistência e atacadistas (2); Subsistência e varejistas (3). }\end{array}$ \\
\hline & $\begin{array}{l}\text { 7. Iluminação utilizada na residência - variável que indica o tipo de iluminação utilizada na } \\
\text { residência, pode ser energia elétrica, lampião a querosene / gás ou velas: Lampião a } \\
\text { querosene ou a gás ou lamparina e/ou velas (1); Energia elétrica (2). }\end{array}$ \\
\hline \multirow{7}{*}{ 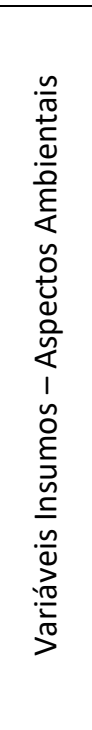 } & $\begin{array}{l}\text { 8. Destino do lixo doméstico - variável que indica a destinação do lixo do assentado, } \\
\text { podendo ser: queimado, enterrado, jogado a céu aberto ou coletado: Queimado ou jogado a } \\
\text { céu aberto (1); Enterrado (2); Coletado (3). }\end{array}$ \\
\hline & $\begin{array}{l}\text { 9. Controle de pragas na unidade produtiva - variável que indica a existência do controle de } \\
\text { pragas, podendo ser: Agrotóxico, nenhum método, biológico: Agrotóxico (1); Nenhum } \\
\text { método (2); Biológico (3). }\end{array}$ \\
\hline & $\begin{array}{l}\text { 10. Utilização de fogo nas atividades agropecuárias - variável binária (Sim ou Não), } \\
\text { indicando se utiliza fogo nas atividades agropecuárias. }\end{array}$ \\
\hline & 11. Plantio de árvore para conservação do solo - variável binária (Sim ou Não). \\
\hline & 12. Existência de sistema de esgoto ou fossa - variável binária (Sim ou Não). \\
\hline & 13. Utilização de rotação de cultura - variável binária (Sim ou Não). \\
\hline & $\begin{array}{l}\text { 14. Utilização da prática de plantio para evitar a degradação do solo - variável binária (Sim } \\
\text { ou Não). }\end{array}$ \\
\hline
\end{tabular}

Fonte: Formulário Pesquisa de campo, 2014.

A normalização adotada neste estudo utiliza o método descrito por Angulo-Meza et al (2005) que não considera os valores máximos e mínimos efetivamente atingidos para a eficiência e o número de DMU's na fronteira para cada quantidade de variáveis, mas sim, os valores extremos teoricamente alcançáveis. O número de DMU's na fronteira está no conjunto $\{1,2,3, \ldots, n\}$, sendo que " $n$ " é o número total de DMU's e a eficiência média também vai estar classificada no 
intervalo [0 até 1]. Portanto, para obter a normalização das eficiências médias para cada conjunto de variáveis, levou-se em conta que quanto maior a eficiência média, maior deve ser o valor dessa variável (ANGULO-MEZA et al, 2007).

Para obter a normalização da quantidade de DMU's eficientes para cada conjunto de variáveis, considera-se que quanto maior o número de DMU's na fronteira, menor é o valor da variável (SOARES DE MELLO et al, 2005).

A aplicação da normalização foi usada em cada etapa do método para escolher uma próxima variável a ser inserida ou que irá compor o modelo de análise. No caso do número de variáveis não ser grande, pode ser calculada para todas as combinações possíveis de inputs e outputs, permitindo que o conjunto final de variáveis a ser escolhidas seja aquele que apresentar o maior índice (ANGULO-MEZA et al, 2005; SENRA et al, 2007; SOARES DE MELLO et al, 2006).

No quadro 2 estão discriminados os intervalos de escalas de índices de eficiência para as DMU's dos assentamentos e com base nestes parâmetros foram feitas análises de eficiências individuais para cada assentamento e agrupada com a análise das amostras de todos os assentamentos (OLIVEIRA, 2012).

Quadro 02 - Intervalos de escalas de índice de eficiência (IE)

\begin{tabular}{ll}
\hline Baixo índice de sustentabilidade & $0,0<\mathrm{IE}<0,5$ \\
\hline Médio índice de sustentabilidade & $0,5<\mathrm{IE}<0,8$ \\
\hline Alto índice de sustentabilidade & $0,8<\mathrm{IE}<1,0$ \\
\hline
\end{tabular}

Fonte: Adaptado de OLIVEIRA (2012).

A opção por esses elementos (sociais, ambientais e econômicos), aparentemente contraditórios entre si, mas imbricados na noção de desenvolvimento sustentável, encontra respaldo em Zaar (2008) que reconhece sua importância nos estudos de uma área ocupada por pequenas produções familiares.

Resultados e discussões

Este estudo se utilizou de variáveis com vistas a produzir uma amostragem dos assentamentos rurais de Corumbá e Ladário/MS no que tange a capacidade do desenvolvimento de iniciativas da agricultura de base familiar ser capaz de promover relacionamentos econômico, social e ambiental sustentáveis.

Levou-se em consideração os problemas que envolvem a fixação das famílias de assentados, tanto em decorrência das restrições contidas no próprio ambiente, quanto das relativas às perspectivas de produzirem o próprio sustento e um excedente para geração de receitas, com as quais podem prover investimentos e sua resistência no campo.

Na Tabela 1 é demonstrada a análise das variáveis de insumos (contendo aspectos econômicos, sociais e ambientais da produção dos assentados), coletadas nas amostragens realizadas nos assentamentos e analisadas frente à produção (que no estudo foi considerada a geração de renda por parte das famílias dos assentados). 
Tabela 01 - Desempenho de eficiência socioeconômica e ambiental individual por assentamentos de Corumbá e Ladário/MS.

\begin{tabular}{|c|c|c|c|c|c|}
\hline \multirow{2}{*}{$\begin{array}{l}\text { Índices de } \\
\text { Eficiência }\end{array}$} & \multicolumn{4}{|c|}{ Quantidade de DMU's } & \multirow[b]{2}{*}{ Total } \\
\hline & $\begin{array}{l}\text { Assentamentos } \\
\text { Tamarineiro I e II }\end{array}$ & $\begin{array}{l}\text { Assentamento } \\
\text { Paiolzinho }\end{array}$ & $\begin{array}{c}\text { Assentamento } \\
\text { Taquaral }\end{array}$ & $\begin{array}{c}\text { Assentamento } \\
72\end{array}$ & \\
\hline 1 & 1 & 1 & 9 & 4 & 15 \\
\hline 0,9 & 18 & & 1 & & 19 \\
\hline 0,8 & 1 & & & 6 & 7 \\
\hline 0,7 & 7 & & & & 7 \\
\hline 0,6 & 21 & 18 & 40 & 6 & 85 \\
\hline 0,5 & & & 1 & & 1 \\
\hline 0,4 & & & & 2 & 2 \\
\hline 0,3 & 2 & & & & 2 \\
\hline 0,2 & 64 & 10 & 9 & 12 & 95 \\
\hline 0,1 & 37 & & & & 37 \\
\hline Total & 151 & 29 & 60 & 30 & 270 \\
\hline
\end{tabular}

Fonte: Pesquisa de campo, 2014.

Pode-se constatar que no assentamento Tamarineiro, 13\% das DMU's demonstraram índices de alta eficiência de sustentabilidade, sendo que apenas uma DMU's alcançou um índice de 1,0. Contudo, $19 \%$ das DMU's mostraram-se com índices médios e $68 \%$ apresentaram baixo índice de eficiência de sustentabilidade. Portanto, um elevado nível de baixa eficiência que revela fragilidade das atividades dos assentados como geradoras de renda e consequentemente sustentabilidade socioeconômica e ambiental.

O assentamento Paiolzinho obteve, comparativamente ao assentamento Tamarineiro II, índices de alta eficiência de sustentabilidade menores (3\%), porém um quantitativo de DMU's bastante inferior (35\%). Prevaleceram os índices médios de eficiência de sustentabilidade, perfazendo $62 \%$ das DMU's.

O assentamento Taquaral apresentou os menores índices (15\%) de baixa eficiência de sustentabilidade. Por outro lado, $17 \%$ das DMU's pesquisadas mostraram-se com índice alto de eficiência de sustentabilidade e $68 \%$ com média eficiência de sustentabilidade.
O assentamento 72, de Ladário, apresentou os maiores índices de alta eficiência de sustentabilidade (33\%), tendo $20 \%$ com média e $47 \%$ das DMU's com baixo índice de eficiência de sustentabilidade.

Quando se distribui os resultados em faixas de índices de eficiência de sustentabilidade (Figura 3) vislumbra-se que $88 \%$ das DMU's pesquisadas encontram-se sob risco de declínio de sustentabilidade. Isso porque o acúmulo de variáveis/fatores limitantes das condições dos assentados como: fertilidade e produtividade do solo, baixa qualificação, escassez de água, descontinuidade produtiva, parco envolvimento de familiares na composição da mão de obra comprometem a ascendência de resultados que possibilitem que os lotes (DMU's) tenham perspectivas de serem sustentáveis social, econômica e ambientalmente.

Além disso, não se verifica uma sinergia entre a situação econômica objetiva da região com as comunidades rurais (com sua história, sua trajetória econômica, sua população, seu capital social, patrimônio, etc.) na orientação produtiva. As instituições de pesquisa (Universidade Federal de Mato Grosso do Sul e Embrapa Pantanal) presentes, apesar de quase 
meio século de existência, não solidificaram ações continuadas (em parte explicada pela elevada rotatividade de seus pesquisadores motivada pela dificuldade de permanência na fronteira) em prol do desenvolvimento local e regional. Na visão de Putnam (1996) essas institucionalidades poderiam puxar as comunidades, elevando o grau de cooperação e de empreendedorismo territorial.

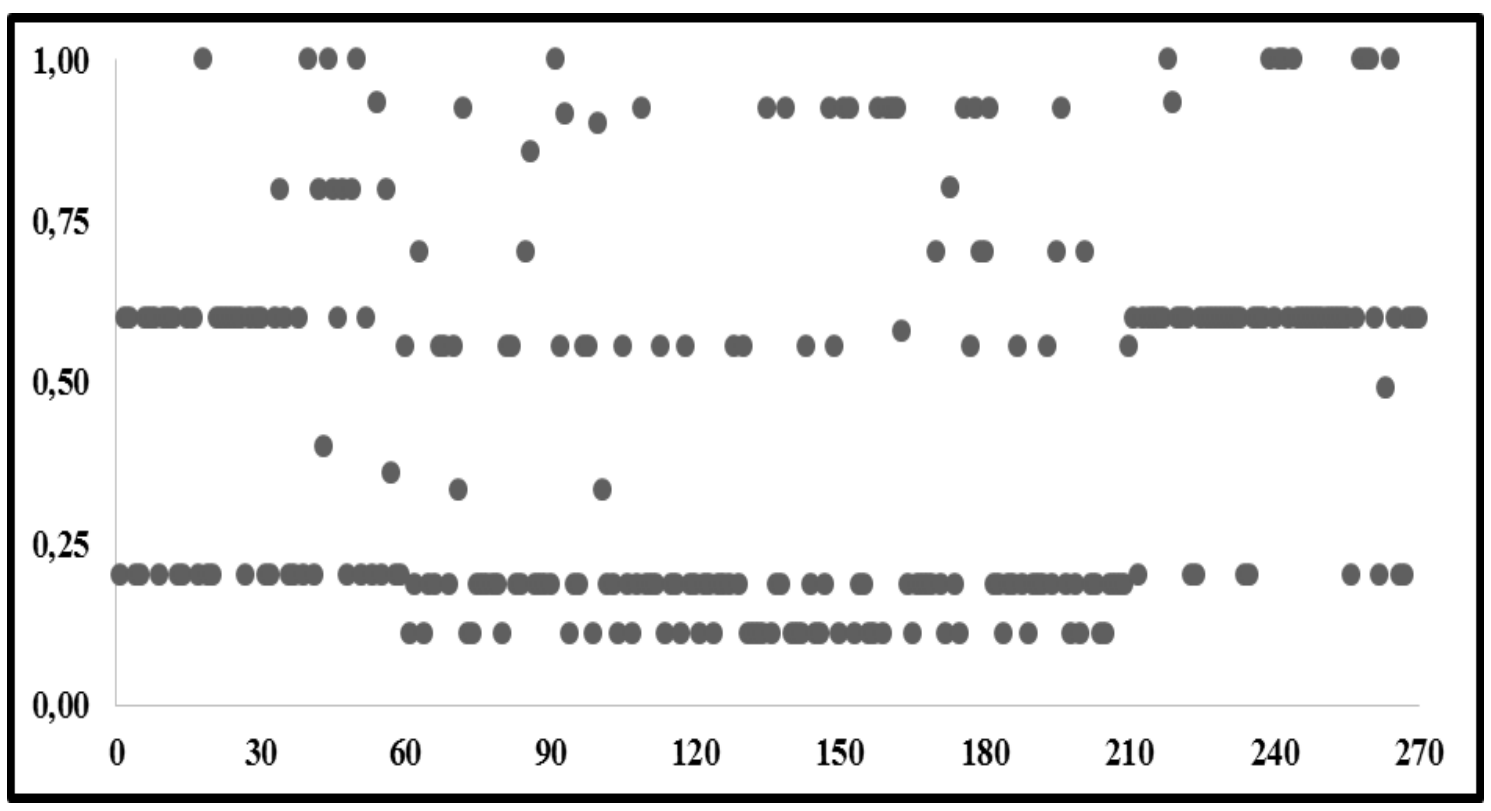

Figura 03 - Sustentabilidade socioeconômica e ambiental de análise individual dos assentamentos de Corumbá e Ladário/MS, a partir DEA/CCR. Fonte: Pesquisa de campo, 2014.

Quando se reúne todas as DMU's investigadas, observa-se que os assentamentos rurais de Corumbá e Ladário apresentam baixo índice de eficiência de sustentabilidade (51\%), enquanto $37 \%$ contam com médio e apenas $12 \%$ com índice alto de eficiência de sustentabilidade. Isso demonstra que existem demandas importantes no setor da agricultura de base familiar imprescindíveis para que as atividades dos assentados possam ser fatores importantes para a construção da sustentabilidade socioeconômica e ambiental nos assentamentos rurais no Pantanal sul-mato-grossense (Tabela 2).

A partir da análise em conjunto de todas as 270 DMU's pesquisadas foram obtidos resultados das relações de eficiência entre elas, independente dos locais individualmente, mas considerando as variáveis de insumos e de produto no contexto global da pesquisa.

Tabela 02 - Classificação da sustentabilidade socioeconômico e ambiental de assentamento em análise individual por assentamento de Corumbá e Ladário/MS.

\begin{tabular}{c|l|c}
\hline DMU & Intervalo & Escalas \\
\hline 137 & Baixo Índice de Sustentabilidade & $0<\mathrm{IE} \leq 0,5$ \\
\hline 99 & Médio Índice de Sustentabilidade & $0,5<\mathrm{IE} \leq 0,8$ \\
\hline 34 & Alto Índice de Sustentabilidade & $0,8<\mathrm{IE} \leq 1,0$ \\
\hline
\end{tabular}

Fonte: Pesquisa de campo, 2014. 
Assim, nos assentamentos Paiolzinho, Tamarineiro II, Taquaral e 72, o índice alto de eficiência de sustentabilidade apresenta os percentuais de $26 \%, 3 \%, 53 \%$ e $30 \%$, respectivamente (Tabela 3 ). Vale dizer que o melhor resultado do assentamento Taquaral contrasta com os $17 \%$ obtidos na relação individual com a amostra somente do assentamento. $\mathrm{O}$ índice médio de eficiência de sustentabilidade foi, respectivamente, de $7 \%$, $10 \%, 10 \%$ e $20 \%$. Observa-se, portanto, um forte declínio percentual do índice médio de eficiência de sustentabilidade nas DMU's quando comparado com as análises individuais.

Tabela 03. Desempenho de eficiência socioeconômica e ambiental agrupado dos assentamentos de Corumbá e Ladário/MS.

\begin{tabular}{|c|c|c|c|c|c|}
\hline \multirow{2}{*}{$\begin{array}{l}\text { Índices de } \\
\text { Eficiência }\end{array}$} & \multicolumn{4}{|c|}{ Quantidade de DMU's } & \multirow[b]{2}{*}{ Total } \\
\hline & $\begin{array}{l}\text { Assentamentos } \\
\text { Tamarineiro I e II }\end{array}$ & $\begin{array}{l}\text { Assentamento } \\
\text { Paiolzinho }\end{array}$ & $\begin{array}{c}\text { Assentamento } \\
\text { Taquaral }\end{array}$ & $\begin{array}{c}\text { Assentamento } \\
72\end{array}$ & \\
\hline 1 & 39 & 1 & 31 & 9 & 80 \\
\hline 0,9 & & & & & 0 \\
\hline 0,8 & & & 1 & & 1 \\
\hline 0,7 & & & & & 0 \\
\hline 0,6 & 8 & 1 & 5 & 5 & 19 \\
\hline 0,5 & 2 & 2 & 1 & 1 & 6 \\
\hline 0,4 & & & & & 0 \\
\hline 0,3 & 65 & 15 & 12 & 6 & 98 \\
\hline 0,2 & 37 & 10 & 10 & 9 & 66 \\
\hline 0,1 & & & & & 0 \\
\hline Total & 151 & 29 & 60 & 30 & 270 \\
\hline
\end{tabular}

Fonte: Pesquisa de campo, 2014.

A Figura 4 demonstra o comportamento dos índices de eficiência obtidos nos assentamentos pesquisados que evidencia o distanciamento da grande maioria das DMU's de resultado mais eficiente. Potencialmente, as
DMU's ineficientes influenciam as demais de forma negativa, podendo contaminar as já incipientes formas de apoio às comunidades assentadas, na conservação do ambiente e na geração de renda. 


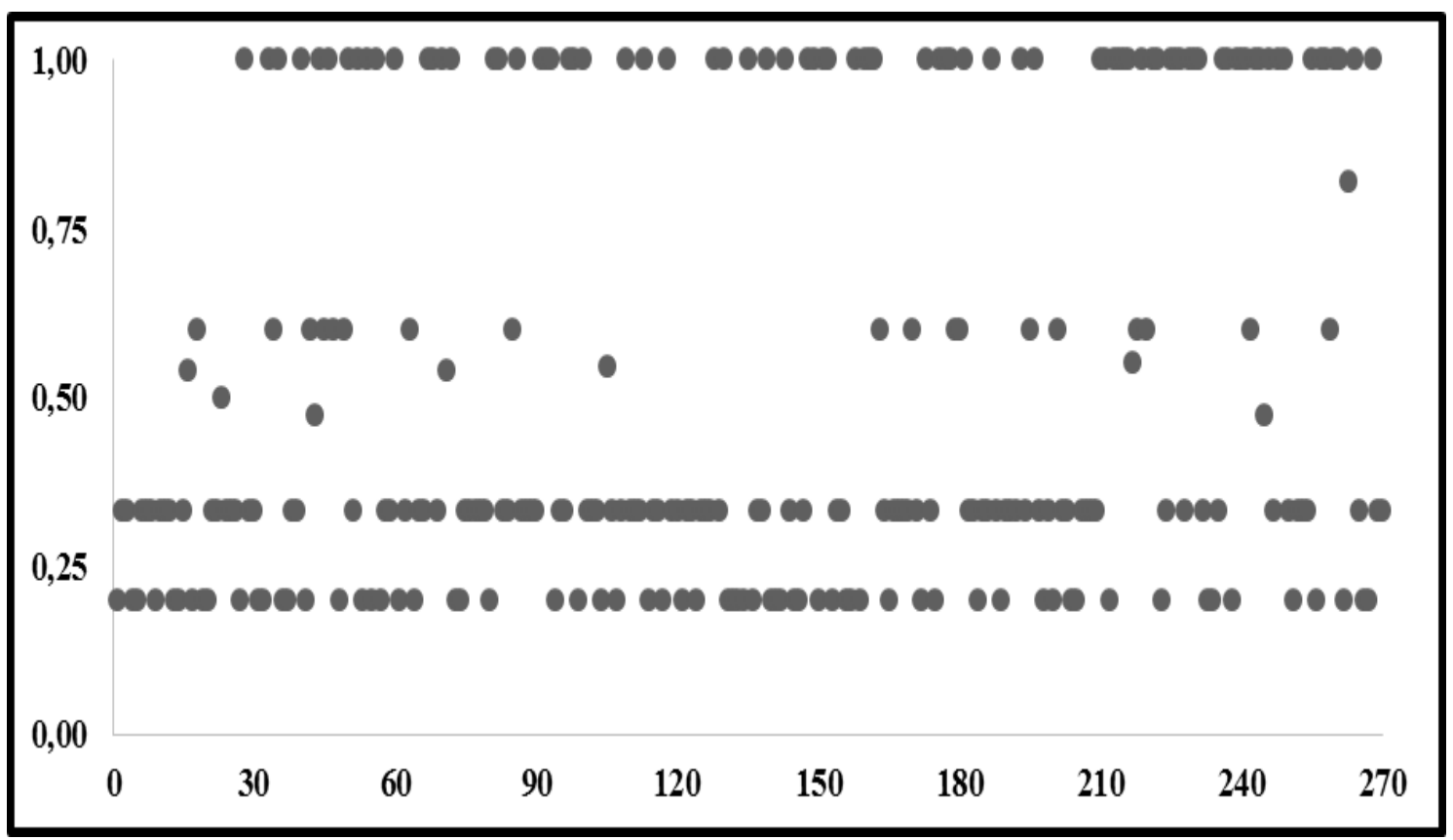

Figura 04. Sustentabilidade socioeconômica e ambiental de análise agrupada dos assentamentos de Corumbá e Ladário/MS, a partir DEA/CCR. Fonte: Pesquisa de campo, 2014.

No agrupamento das DMU's, as variáveis de insumos apresentaram uma competitividade maior no benchmark (relativo ao melhor posicionamento dentre as famílias pesquisadas) ocasionando maior declínio da eficiência, e consequentemente uma situação representativamente mais latente de insustentabilidade socioeconômica e ambiental nos assentamentos.

No resultado agrupado, 62\% das DMU's apresentam índice baixo, $8 \%$ índice médio e 30\% possuem índice alto de eficiência de sustentabilidade (Tabela 4). No computo geral,
70\% das DMU's pesquisadas apresentam significativa fragilidade dos resultados de renda da agricultura dos assentados, com consequências negativas para a sustentabilidade de todo o sistema dos assentamentos.

Os resultados obtidos no estudo indicam a necessidade de construção de redes de apoio à agricultura de base familiar presentes nos assentamentos de Corumbá e Ladário. Caso contrário, todo um potencial produtivo e agregador de valor de recursos naturais poderá sucumbir diante de iniciativas muito mais hostis e perversas ao ambiente

Tabela 04 - Classificação da sustentabilidade socioeconômico e ambiental de assentamento em análise agrupada dos assentamentos de Corumbá e Ladário/MS.

\begin{tabular}{c|c|c}
\hline DMU & Intervalo & Escalas \\
\hline 167 & Baixo Índice de Sustentabilidade & $0<\mathrm{IE} \leq 0,5$ \\
\hline 22 & Médio Índice de Sustentabilidade & $0,5<\mathrm{IE} \leq 0,8$ \\
\hline 81 & Alto Índice de Sustentabilidade & $0,8<\mathrm{IE} \leq 1,0$ \\
\hline
\end{tabular}

Fonte: Pesquisa de campo, 2014.

Analisando os resultados das DMU's, tanto no contexto do assentamento quanto no conjunto da agricultura de base familiar de Corumbá e Ladário, nota-se importantes níveis de fragilidade. Vale destacar que não existem organizações cooperativas e que a produção individual amplifica os riscos já próprios das atividades agrícolas, conforme destacado por 
Saquet e Alves (2014), pois fica mais complicado acessar mercados e garantir a escala e continuidade produtiva.

Já existem algumas iniciativas de produção agroecológica de hortaliças em algumas parcelas camponesas dos assentamentos rurais de Corumbá e Ladário. Vários trabalhos apontam que a agroecologia pode ser uma importante aliada dos assentados rurais para resistência/permanência no meio rural. Dentre os quais, pode-se citar Piccin e Moreira (2006), Chelotti (2007) e Marcos (2007).

É importante destacar que uma das limitações do modelo de avaliação da sustentabilidade econômica, social e ambiental é o fato de não conseguir mensurar a importância da produção de subsistência para as famílias camponesas. Coelho e Fabrini (2014, p. 73) advertem que "não se pode interpretar a subsistência somente como produção de autoconsumo". Ela é formada por "um conjunto de necessidades que garantem a reprodução física e social dos indivíduos". Nessa perspectiva, o autoconsumo é uma parte da subsistência que explica, por vezes, a permanência/resistência de uma família no campo. Possivelmente isso esclarece o fato de, neste trabalho, uma DMU ter apresentado baixo índice de sustentabilidade e seu ocupante estar a mais de 20 anos no local.

Outro ponto importante a ser mencionado é que a predominância dos baixos índices de sustentabilidade está relacionada à incapacidade do Estado no papel de articulador e promotor da produção rural para abastecimento de sua área urbana. Não se afirma, aqui, a total omissão do Estado, mas sua ineficiência na construção/condução de políticas públicas para o setor que sejam capazes de estimular excedentes produtivos comercializáveis.

Os assentamentos rurais estudados, apesar de possuírem mais de 10 anos de existência, ainda não são emancipados. Essa situação serve como justificativa para o não comprometimento das diferentes esferas do governo: a Federal, com o INCRA (Instituto Nacional de Colonização e Reforma Agrária) que entende que o tempo de existência dos assentamentos remete aos demais entes federativos; a estadual, que alega a falta de legitimidade para atuar, pois, tecnicamente os assentamentos são de responsabilidade do INCRA; e a municipal, com poucos recursos, que opera entre o dilema de atender uma população que está em seu território, mas com vinculação formal na esfera federal. A consequência é a deficiência na assistência técnica e no acompanhamento da condição de vida das famílias camponesas.

\section{CONSIDERAÇÕES FINAIS}

A reforma agrária é, sem dúvida, um importante mecanismo de reconstrução do ambiente rural, possibilitando a reterritorialização de agricultores assentados em áreas até então improdutivas. Contudo, em que pesem as políticas públicas para comercialização dos produtos da agricultura de base familiar, ainda é preciso maiores investimentos para permanência no meio rural.

Vários assentamentos rurais foram instalados em áreas com grandes dificuldades para produção e ou comercialização. Em Corumbá e Ladário, no Oeste sul-mato-grossense, estão em áreas de solos férteis, mas com restrições de água (para consumo e produção), estradas (precárias na maior parte do tempo) e climáticas (concentração das chuvas no verão e elevadas temperaturas na maior parte do ano).

Os níveis de eficiência de sustentabilidade obtidos no estudo em relação aos assentamentos Tamarineiro II, Paiolzinho, Taquaral e 72 demonstraram a existência de uma vulnerabilidade latente em sua capacidade de geração de renda e consequente conservação do ambiente e dos recursos naturais. $O$ baixo poder de agregar valor à produção, aliado às características da natureza, pode onerar ainda mais o ambiente, a ponto de comprometer toda uma cadeia ecossistêmica.

A busca pela sustentabilidade produtiva dos camponeses exigirá um papel proativo das instituições de pesquisa e do poder público com ações que incentivem e apoiem os assentados para incrementar sua capacidade de 
permanência/resistência no meio rural. Análises e diagnósticos que permitam entender e conciliar a produtividade rural com a sustentabilidade do ambiente são instrumentos importantes nesse processo. Contudo, é fundamental a evolução das organizações sociais, que hoje estão fragilizadas nos assentamentos, para associações e cooperativas de produção mais vibrantes.

A ampliação de práticas agroecológicas tende fortalecer as possibilidades camponesas pelo baixo custo produtivo, pela qualidade dos alimentos produzidos $\mathrm{e}$ recuperação/manutenção das qualidades dos solos. As DMU's que apresentaram os melhores resultados são exatamente aquelas que estão desenvolvendo práticas agroecológicas, ainda em estágio embrionário, mas que já acessam políticas públicas como PNAE (Programa Nacional de Alimentação Escolar) e PAA (Programa de Aquisição de Alimentos).

\section{REFERÊNCIAS}

ACSELRAD, H.; LEROY, J-P. Novas premissas da sustentabilidade democrática. Cadernos de debate Brasil Sustentável e Democrático, n. 1. Rio de Janeiro: FASE, 1999, pp. 11-47.

ALTIERI, M. Agroecologia, agricultura camponesa e soberania alimentar. São Paulo: Expressão Popular; Rio de Janeiro: AS-PTA, 2012.

ALTIERI, Miguel. Agroecologia: a dinâmica produtiva da agricultura sustentável. Porto Alegre: Ed. UFRGS, 1998.

ANGULO MEZA, L.; BIONDI NETO, L.; SOARES DE MELLO, J. C. C. B.; GOMES, E. G. ISYDS Integrated System for Decision Support (SIAD Sistema Integrado de Apoio a Decisão): a software package for data envelopment analysis model. Pesquisa Operacional, Niterói, v. 25, n. 3, p. 493-503, 2005.

ANGULO-MEZA, L., BIONDI NETO, L., SOARES DE MELLO, J. C. C. B.; GOMES, E. G.; FERNADES, A. J. S. Seleção de variáveis em DEA aplicada a uma análise do mercado de energia eléctrica. Investigação Operacional, Rio de Janeiro, v. 27, p. 21-36, 2007.
BANKER, R. D.; CHARNES, A.; COOPER, W. W. Some models for estimating technical and scale inefficiencies in data envelopment analysis. Management Science, v. 30, n. 9, p. 1078-1092, 1984.

CAPORAL, F. R.; COSTABEBER, J. A. Agroecologia e desenvolvimento rural sustentável: perspectivas para uma nova Extensão Rural. In: ETGES, V. E. (org.). Desenvolvimento rural: potencialidades em questão. Santa Cruz do Sul: EDUSC, 2001, p.19-52.

CHARNES, A; COOPER, W. W; RHODES, E. Data Envelopment Analysis: theory, methodology and applications. USA: Kluwer Academic Publishers, 1994.

CHELOTTI, M. C. Agroecologia em assentamentos rurais: estratégia de reprodução camponesa na Campanha Gaúcha (RS). Agrária, São Paulo, n. 7, 2007, p. 94-118.

COELHO, D. C.; FABRINI, J. E. Produção de subsistência e autoconsumo no contexto de expansão do agronegócio. Revista NERA, Presidente Prudente, Ano 17, n. 25, 2014, p. 7187.

COSTA, E. A. Mobilidade e fronteira: as territorialidades dos jovens de Corumbá, Brasil. Revista Transporte y Territorio, n.9, 2013, p.6586.

COSTA, E. A. Ordenamento territorial em áreas de fronteira. In: COSTA, E.A; OLIVEIRA, M.A.M. Seminário de estudos fronteiriços. Campo Grande: Editora UFMS, 2009, p. 61-78.

GLIESSMAN, S. Agroecologia: processos ecológicos em agricultura sustentável. Porto Alegre: Ed. UFRGS, 2000.

FERNANDES, B. M. Questão Agrária, Pesquisa e MST. São Paulo: Cortez Editora, 2001.

IBGE. Instituto Brasileiro de Geografia e Estatística. Censo agropecuário 2006. Rio de Janeiro: IBGE, 2006. 